\section{Chronic renal failure associated with topical application of paraphenylenediamine}

Paraphenylenediamine ("para"), a derivative of paranitroaniline, is widely used as a hair dye. It has several toxic effects, of which asthma and dermatitis are common. About $4 \%$ of apparently normal subjects are sensitive to it, and $1 \%$ are acutely sensitive. ${ }^{1}$ We report two cases of vasculitis and crescentic glomerulonephritis after prolonged topical application.

\section{Case 1}

A 51 year old woman who habitually used a henna hair dye with a paraphenylenediamine base was admitted to hospital with chronic renal failure; creatinine clearance was $11 \mathrm{ml} / \mathrm{min}$. Clinical examination showed uraemia, normotension, dependent oedema, and several small nodular lesions over her knuckles and elbows. Blood urea concentration was $32 \mathrm{mmol} /(192 \mathrm{mg} / 100 \mathrm{ml})$, serum creatinine $680 \mu \mathrm{mol} / /(7.7 \mathrm{mg} / 100 \mathrm{ml})$, and haemoglobin $86 \mathrm{~g} / \mathrm{l}$; she had proteinuria of $6 \mathrm{~g} / 24 \mathrm{~h}$. Biopsy of the skin lesions showed vasculitis, and percutaneous renal biopsy showed crescentic glomerulonephritis.

Prednisolone $40 \mathrm{mg}$ daily resulted in improvement initially, but poor compliance led to her readmission four years later in end stage renal failure. Despite peritoneal dialysis and steroid treatment she died from coliform bronchopneumonia.

At postmortem examination there was no evidence of healed vasculitis both kidneys were extremely small, and histologically there was considerable hyalinisation of the glomeruli. Many of the tubules were distended with colloid casts, and there was fine fibrosis with an infiltrate of lymphocytes in the interstitial tissue. The interlobar and arcuate arteries showed thickening of their walls but no evidence of arteritis.

\section{Case 2}

A previously healthy 62 year old woman who had used a hair dye with a paraphenylenediamine base for two years was admitted to hospital in renal failure after three weeks of lethargy, anorexia, myalgia, and swelling of the ankles. She required emergency peritoneal dialysis for life threatening hyperkalaemia. Clinical examination showed uraemia, anaemia, signs of left basal consolidation, and considerable oedema of the legs. There were two small nodular lesions over her left elbow. Blood urea concentration was $61 \mathrm{mmol} /(366 \mathrm{mg} / 100 \mathrm{ml})$, serum creatinine $841 \mu \mathrm{mol} / \mathrm{l}(9 \cdot 5 \mathrm{mg} / 100 \mathrm{ml})$, and haemoglobin $107 \mathrm{~g} /$. Biopsy of the lesions on her elbow showed allergic vasculitis, and she was therefore given prednisolone $20 \mathrm{mg}$ daily. She remained oliguric and three weeks after admission developed non-reversible ventricular fibrillation while receiving haemodialysis.

Postmortem examination showed occlusion of the right coronary artery by recent haemorrhage into an atheromatous plaque and a healed posterior wall myocardial infarct. The lungs were congested, and multiple white nodules $1-2 \mathrm{~cm}$ in diameter were noted throughout. Histologically these consisted of a granulomatous inflammatory process with central fibrinoid necrosis, and there was also fibrinoid necrosis and an acute inflammatory infiltrate in the vascular channels, consistent with Wegener's granulomatosis. Both kidneys were enlarged and pale with histological and immunological evidence of crescentic glomerulonephritis.

\section{Comment}

D'Arcy reported acute renal failure with angioneurotic oedema in Sudanese women who apply a mixture of paraphenylenediamine and henna to the skin. ${ }^{2}$ Henna is used by the Islamic community to dye hair, skin, and nails for important occasions. The traditional method of application requires that the woman (or bridegroom) remains immobile for about six hours on two successive days, but this process can be reduced to a matter of minutes by adding paraphenylenediamine to the henna. Over 20 cases of toxicity after use of this combination of dyes occurred over two years in Khartoum alone. Cases of acute tubular necrosis have occurred after suicidal ingestion of paraphenylenediamine. ${ }^{34}$

Bernis et al reported remission of Goodpasture's syndrome after avoidance of all chemicals used in the hairdressing trade. ${ }^{5}$ Although neither of our patients had a positive titre of antiglomerular basement membrane antibodies, a distinct similarity exists.

The possible toxic effects of paraphenylenediamine, ${ }^{1}$ and other reports, ${ }^{2-5}$ suggest that the lesions in our patients may have been caused by prolonged use of the substance. Hair dyes containing it are widely available for application at home; as well as inquiring about drugs ingested, doctors should ask women patients about their use of hair dyes.
1 Wade A, ed. Martindale; the extra pharmacopoeia. 27th ed. London: Pharmaceutical Press, 1977:1792.

2 D'Arcy PF. Fatalities with the use of a henna dye. Pharmacy International 1982;3:217-8.

3 Chug KS, Malik GH, Singhal PC. Acute renal failure following paraphenylene diamine (hair dye) poisoning: report of two cases. 7 Med 1982:13:131-7.

4 Suliman SM, Homeida M, Aboud OI. Paraphenylenediamine induced acute tubular necrosis following hair dye ingestion. Hum Toxicol 1983:2:633-5.

5 Bernis P, Hamels J, Quoidbach A, Mahieu PM, Bouvy P. Remission of Goodpasture's syndrome after withdrawal of an unusual toxic. Clin Nephrol 1985;23:312-7.

(Accepted 2 October 1986)

Renal Unit, Belfast City Hospital, Belfast BT9 7AB, Northern Ireland

J H BROWN, MRCP, registrar

M G MCGEOWN, CBE, MD, FRCP, consultant nephrologist

Department of Pathology, Belfast City Hospital, Belfast BT9 7AB

B CONWAY, MB, senior registrar

Institute of Pathology, Queen's University of Belfast, Belfast BT12 6BA

C M HILL, MD, MRCPATH, senior lecturer and consultant pathologist

Correspondence to: Dr Brown.

\section{Severe bradycardia due to interaction of timolol eye drops and verapamil}

Drugs administered topically, such as eye drops, may be absorbed into the systemic circulation and so may cause unwanted effects including interactions with drugs administered orally. ${ }^{1} \beta$ Blockers and the calcium antagonist verapamil given orally may interact, causing sinus node dysfunction ${ }^{2}$ or atrioventricular nodal conduction delay. ${ }^{3} \mathrm{We}$ report a case in which a topical $\beta$ blocker and oral verapamil combined to cause sinus node dysfunction with severe bradycardia.

\section{Case report}

A 64 year old man with chronic simple glaucoma was admitted for monitoring of intraocular pressure, which had been controlled for the past two years with pilocarpine eye drops $2 \%$ four times daily and timolol eye drops $0.5 \%$ twice daily. He also suffered from chronic stable angina, for which he had received oral verapamil $160 \mathrm{mg}$ twice daily for the past 12 months. There was no history of myocardial infarction, hypertension, or syncope. On examination he was well but had an irregular bradycardia of 36 beats $/ \mathrm{min}$. Blood pressure was $130 / 70 \mathrm{~mm} \mathrm{Hg}$. Heart sounds were normal, and there were no signs of cardiac failure. A neurological examination yielded normal results.

Twelve lead electrocardiography showed a bradycardia of 36 beats $/ \mathrm{min}$ with a wandering atrial pacemaker; there was no evidence of recent or past myocardial infarction. Although he was asymptomatic, this bradycardia was considered to be undesirable and nifedipine $10 \mathrm{mg}$ thrice daily was therefore substituted for the verapamil. Within 48 hours his pulse had risen to 78 beats/min, and repeat electrocardiography showed a return to sinus rhythm.

\section{Comment}

Calcium antagonists and $\beta$ blockers may be usefully combined to treat angina. ${ }^{4}$ The combination of $\beta$ blockers and the calcium antagonist verapamil, however, has been reported to cause sinus node dysfunction, ${ }^{2}$ atrioventricular nodal conduction delay, ${ }^{4}$ and complete heart block. ${ }^{3}$

About $80 \%$ of a topical dose of timolol is absorbed from the conjunctiva and nasal mucosa and enters the systemic circulation, thus bypessing the "first pass" hepatic metabolism, which normally accounts for 75\% of the oral dose. ${ }^{15}$ Fairly small doses administered topically may result in systemic $\beta$ adrenoreceptor blocking effects. ${ }^{1}$ We believe this to be the first reported case of the combination of a topical $\beta$ blocker and oral verapamil causing sinus node dysfunction with severe bradycardia. Though the verapamil itself may have caused the arrhythmia, the combination of the two drugs seems more likely to have been responsible. When the verapamil was changed to a calcium antagonist that has no effect on conducting tissue the heart rate and rhythm returned to normal within $\mathbf{4 8}$ hours.

This case emphasises that drugs may interact when given by different routes and that an adequate drug history must include topically administered drugs such as eye drops. We recommend that patients receiving topical 
$\beta$ blockers who require a calcium antagonist for the treatment of angina are prescribed one that has no effect on cardiac conducting tissue.

We thank Mrs Sheila Haugh for typing this manuscript.

1 Van Buskirk EM, Fraunfelder FT. Timolol and glaucoma. Arch Ophthalmol 1981;99:696.

Findlay IN, Gillen G, Elliot AT, Dargie HJ. The treatment of angina pectoris with calcium channel and beta-blockers, efficacy and effect on cardiac function. [Abstract.] $f$ Am Coll Cardiol 1984;3:482.

3 Hutchison SJ, Lorimer AR, Lakhdar A, McAlpine SG. $\beta$ Blockers and verapamil: a cautionary tale. BrMed J 1984;289:659-60.

4 Johnston DL, Lesoway R, Humen DP, Kostor WJ. Clinical and haemodynamic evaluation of propranolol in combination with verapamil, nifedipine and diltiazem in exertional angina pectoris: a placebo-controlled, double-blind, randomised crossover study. Am $\mathcal{f}$ Cardiol 1985;55:680-7.

5 Hitchings RA. Beta-blockers in the treatment of chronic simple glaucoma. $\mathrm{Br}$ Med $\mathcal{F}$ 1982;285: $84-5$.

(Accepted 30 Seprember 1986)

University Department of Medical Cardiology, Royal Infirmary, Glasgow G31 2ER

S D PRINGLE, MRCP, registrar

Department of Ophthalmology, Gartnavel General Hospital, Glasgow G11

CAROLINE J MACEWEN, FRCS, registrar

Correspondence to: Dr Pringle.

\section{Sweat osmolality in Down's syndrome and cystic fibrosis in an Indian population}

Several reports have indicated that sweat electrolyte concentration or osmolality is increased in patients with cystic fibrosis, ${ }^{1-3}$ whereas little is known about other clinical conditions in which sweat osmolality is altered. There is also a gap in our knowledge about physiological and pathological factors that could affect the sweat osmolality value. Furthermore, no studies of sweat osmolality in an Indian population have to our knowledge been reported. We therefore measured sweat osmolality in various clinical conditions in an Indian population.

\section{Patients, methods, and results}

Apparently healthy subjects of different ages and sex were invited to be control subjects. Patients were selected from those attending the National Institute of Mental Health and Neuro Sciences mental retardation clinic and from those referred from other centres. Sweat induction and collection was carried out with Webster's sweat collection system, which comprised iontophoretic equipment and a macroduct system, using the procedure described by the manufacturer. Osmolality of the sweat specimens was measured in a vapour pressure osmometer (Wescor, model 5100), which was precalibrated against reference standards ranging from $100 \mathrm{mmol}$ (mosmol) $/ \mathrm{kg}$ to $1000 \mathrm{mmol} / \mathrm{kg}$. Each sample was assayed in triplicate, and the average reading was taken as the final value. The results were analysed by Student's $t$ test.

The normal range of sweat osmolality was established in an Indian subpopulation $(n=830)$ of apparently normal subjects with an age range of 1 to 60 years. Most responded to pilocarpine iontophoresis by sweating $(25-100 / \mu \mathrm{l}$ per single stimulation). On rare occasions, however, some subjects did not respond even to repeated pilocarpine iontophoresis. Sweat osmolality in the normal group as a whole, irrespective of age and sex, ranged from 100 to $150 \mathrm{mmol} / \mathrm{kg}$. When this group was divided on the basis of age and sex a significant difference $(p<0.001)$ in sweat osmolality was observed between men $(113.7$ (SD 9.5) $\mathrm{mmol} / \mathrm{kg} ; \mathrm{n}=60)$ and women $(149 \cdot 8(10 \cdot 1) \mathrm{mmol} / \mathrm{kg} ; \mathrm{n}=100)$ aged 11 to 15 years. In the next age group (16 to 35 years) sweat osmolality remained about the same in both sexes. In $\operatorname{men}(105 \cdot 7(8 \cdot 6) \mathrm{mmol} / \mathrm{kg} ; \mathrm{n}=180)$ and women $(140 \cdot 22(20 \cdot 0) \mathrm{mmol} / \mathrm{kg} ; \mathrm{n}=160)$ aged over 35 , however, the sweat osmolality pattern was similar to that in the group aged 11 to 15.

The figure shows that the highest sweat osmolality in normal subjects, irrespective of sex and age, did not exceed $160 \mathrm{mmol} / \mathrm{kg}$. On the other hand, sweat osmolality in patients with Down's syndrome $(228 \cdot 41(40 \cdot 0) \mathrm{mmo} / \mathrm{kg} ; \mathrm{n}=20)$ and clinically confirmed cystic fibrosis $(240.41(57 \cdot 0) \mathrm{mmol} / \mathrm{kg} ; \mathrm{n}=6)$ was always higher than $160 \mathrm{mmol} / \mathrm{kg}$. Such patients also responded poorly to sweat induction by pilocarpine iontophoresis.

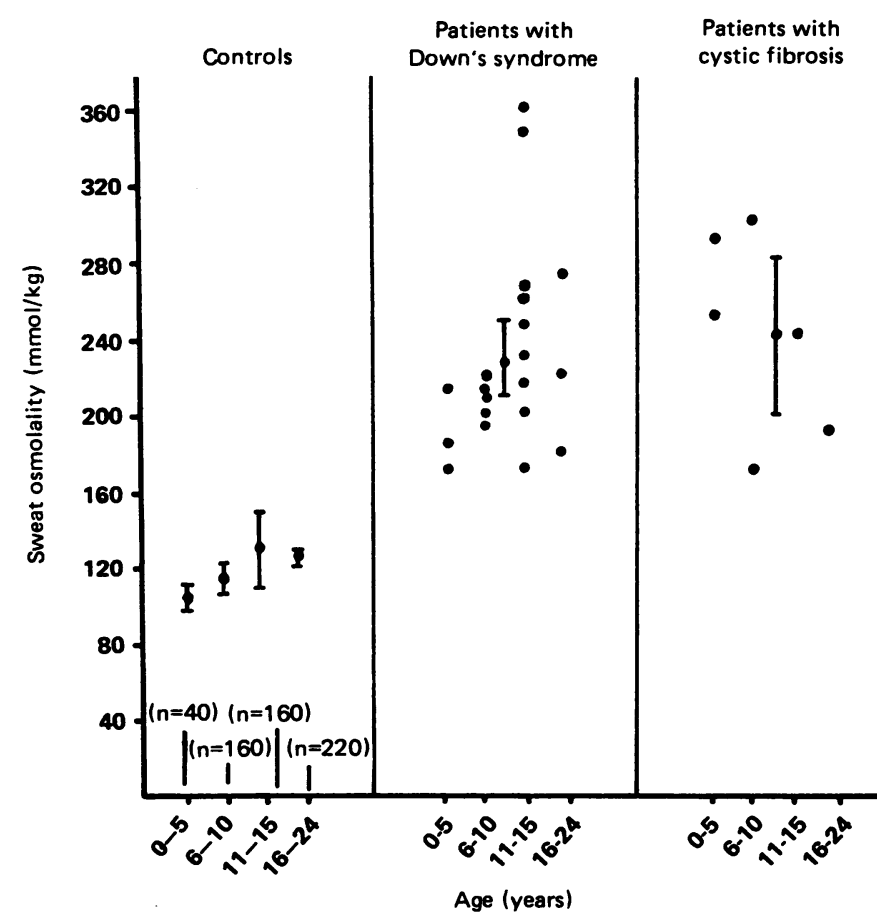

Sweat osmolality in control subjects matched for age and patients with Down's syndrome and cystic fibrosis. Bars represent SD. Mean and SD are given for each age group in control subjects but for whole group in patients with Down's syndrome and cystic fibrosis.

\section{Comment}

An increased sweat electrolyte concentration is usually considered to be a discriminatory test for cystic fibrosis. ${ }^{1-4}$ Recent trends in sweat analysis have shown that sweat osmolality can be used as an alternative to the estimation of electrolyte concentration, ${ }^{5}$ and an increased sweat osmolality is considered to be a confirmatory test for clinically suspected cases of cystic fibrosis. In the present study we noticed that sweat osmolality fluctuates during a person's life span, the changes being associated with the onset of puberty and menopause, implying that hormone state plays a part in sweat physiology. In patients with cystic fibrosis and Down's syndrome response to pilocarpine stimulation in terms of amount of sweat was poor, and the proportion of nonresponders to pilocarpine was significantly higher in these patients $(>10 \%)$ than in the normal population (3\%).

We have thus established a normal range of sweat osmolality in an Indian subpopulation and have highlighted the effect of factors such as age and sex on this characteristic. Furthermore, we have observed a difference in response to pilocarpine stimulation in the patient population ranging from good response (30-100 $\mu \mathrm{l} /$ single stimulation) through poor response (15-30 $\mu$ l sweat after repeated stimulation) to no response. In addition, we observed a consistent increase in sweat osmolality in patients with Down's syndrome and clinically suspected cystic fibrosis.

1 Gibson LE, Cooke RE. A test for concentration of electrolytes in sweat in cystic fibrosis of the pancreas utilizing pilocarpine by iontophoresis. Pediatrics 1959;23:545-9.

2 di Sant' Agnese PA, Darling RC, Perera GA, et al. Abnormal electrolyte composition of sweat in $\mathcal{G}$ cystic fibrosis of the pancreas: clinical significance and relationship to the disease. Pediacrics cystic f16rosis of th:

3 Webster HL, Barlow WK. New approach to cystic fibrosis diagnosis by use of an improved sweat ind

induction/collection system and osmome

5 Davis PB, Rio SD, Muntz JA, Dieckman L. Sweat chloride concentration in adults with pulmonary diseases. Am Reo Respir Dis 1983;128:34-7.

(Accepted 9 September 1986)

Department of Neurochemistry, National Institute of Mental Health and

Neuro Sciences, Bangalore-560029, India

H GEETHA, MSC, lecturer on deputation

K TARANTH SHETTY, PHD, associate professor

Correspondence to: Dr Shetty. 